\title{
The Signal of Applying for a Job Under
}

\section{a Vacancy Referral Scheme*}

\begin{abstract}
We investigate the signalling effect related to participation in active labour market programmes. To this end, we conduct an experiment in which HR professionals make hiring decisions concerning fictitious job candidates who apply either under a job-vacancy referral system or directly. We provide first causal evidence for a substantial adverse effect of referral on the probability of being hired. In addition, we find that employers perceive referred candidates as being less motivated than other candidates.
\end{abstract}

Keywords: signalling; activation policies; job referral; policy evaluation; unemployment. JEL-codes: J68, J23, C91. 


\section{1. Introduction}

2 In order to alter the trend of persistent unemployment over recent decades, the majority of OECD

3 countries have invested vast amounts of public funds in active labour market policies (ALMPs; Martin,

4 2014; Martin \& Grubb, 2001). These investments have logically resulted in a surge in research

5 evaluating the effectiveness of these policy instruments (Card et al., 2010, 2015; Greenberg et al., 2003;

6 Heckman et al., 1999; Kluve, 2010; Liechti et al., 2017). The results of these evaluations are mixed at

7 best. Overall, the effectiveness of ALMPs in terms of exit out of unemployment depends largely on the

8

9 type of ALMP, its target group and the time horizon of the evaluation (Card et al., 2010, 2015; Kluve, 2010; Martin \& Grubb, 2001). Moreover, the few studies that have taken the costs of these programmes into account indicate that the benefits of ALMPs do not outweigh their costs (Albanese et al., 2016; Card et al., 2015; Crépon et al., 2013; Jespersen et al., 2008). The ALMP central to this study, a job-vacancy referral scheme implemented in Flanders, Belgium, exhibits the same mixed effectiveness. This scheme matches vacancies with jobseekers and, subsequently, forces jobseekers to apply for the vacancies matched to them. ${ }^{1}$ While some studies find positive results of this kind of programme with respect to exit out of unemployment (Bollens \& Cockx, 2016; Fougère et al., 2009; van den Berg et al., 2014), others find no impact at all (Engström et al, 2012; van den Berg \& van der Klaauw, 2006). Moreover, some of the studies that present positive effects of job-vacancy referrals show that the higher job-finding rate as a result of referral goes hand in hand with a lower job quality (van den Berg et al., 2016; van den Berg \& Vikström, 2014).

Measuring the effectiveness of these policies in terms of their desired outcomes is in no doubt important. However, if one aims to reform ALMPs to increase their effectiveness, one needs to go beyond measuring and look at possible explanations for the unsatisfactory effectiveness. One possible explanation documented in the literature is the signal associated with ALMPs. Signalling theory states that when individuals are faced with limited information, they will use particular components of this 
information to predict unobserved factors (Arrow, 1973; Blanchard \& Diamond, 1994; Moscarini, 1977; Spence, 1973; Vishwanath, 1983). In this respect, we can expect a positive as well as a negative signal sent to prospective employers by a job-vacancy referral. ${ }^{2}$ On the one hand, candidates applying for a position at the request of a public employment service (PES) have gone through an initial screening process and have been deemed suitable for the position by the PES. In other words, the vacancy referral could be seen as a signal of improved suitability (Bellis et al., 2011). On the other hand, employers could see referred applicants as candidates who do not have the ability to succeed in the labour market on their own and/or only apply to comply with benefit rules (Bonoli \& Hinrichs, 2010; Bellis et al., 2011; Ingold \& Stuart, 2014). As a consequence, being referred to a vacancy has been theoretically related to lower intellectual and/or social abilities (Bellis et al., 2011; Ingold \& Stuart, 2014), lower trainability (Thurow, 1975), negative evaluation by previous employers (Banerjee, 1992; Bikhchandani et al., 1992) and, most commonly cited, lower motivation (Bonoli \& Hinrichs, 2010; Ingold \& Stuart, 2014).

The empirical literature on the signal of ALMPs is limited and mainly of a qualitative nature (Bellis et al., 2011; Bonoli \& Hinrichs, 2010; Ingold \& Stuart, 2014; Liechti et al., 2017). Little or no causal evidence has been presented for signalling as an explanation for the limited effectiveness of these policies. Falk et al. (2005) and Liechti et al. (2017) are notable exceptions. By means of a field experiment, Falk et al. (2005) measure how completing a computer training programme impacts jobfinding rates. More concretely, they compare the call-back rates for job candidates with and without this kind of training. They find that completing a computer training programme does not yield higher call-back rates. Liechti et al. (2017) quantify the signalling value of different types of ALMPs, including training programmes and subsidised employment, by means of a factorial survey experiment. They find that employers do take ALMP participation into account when making hiring decisions, but the signalling effect of this participation can be both positive as well as negative, depending on the potential candidate's distance from the labour market. 
1 To this aim, we conduct a state-of-the-art vignette experiment with human resource (HR) professionals.

2 We ask these participants to make fictitious hiring decisions concerning job candidates described on vignettes. Half of these candidates are indicated as applying under a job-vacancy referral scheme.

4 Besides being rated in terms of hireability, these fictitious candidates are evaluated on statements

5 related to the five potential signals sent by applying in the context of a referral as listed above

6 (motivation, intellectual abilities, social abilities, trainability, and previous unfavourable evaluation by

7 other employers). The data collected by means of this experiment allow us to answer three research

8 questions.

R1: Does applying for a job under a job-vacancy referral scheme yield lower hiring chances?

R2: Is the signalling effect of applying for a job under a vacancy referral scheme heterogeneous by candidate and participant characteristics?

R3: Which particular signals are sent by applying for a job under a vacancy referral scheme?

13 The present study complements the work by Falk et al. (2005) and Liechti et al. (2017) by quantifying 14 the signalling value of a different type of ALMP. In addition, by means of answering R3, we contribute to this literature by being the first to investigate which signal(s) is (are) particularly sent by participation in ALMPs in general and applying under a vacancy referral scheme in particular. This is of particular policy relevance because it shows which prejudices against the unemployed applying for jobs under a job-vacancy referral scheme should be compensated for.

The remainder of the study is structured as follows. Section 2 describes the institutional setting, our experimental design, and the realised data collection. Our research questions are answered in Section 3, where results from analysis of the experimental data are presented. Section 4 concludes, focussing on both the academic and policy implications of our research. 


\section{2. Experiment}

2 To answer R1, R2, and R3, we conducted a vignette experiment. In this kind of experiment, participants

3 are asked to judge fictitious descriptions (presented on vignettes) that differ on a pre-defined number

4 of variables (the vignette factors), which are randomly assigned a value (the vignette-levels; Auspurg \&

$5 \quad$ Hinz, 2014; Jasso, 2006; Rossi \& Nock, 1982; Sauer et al., 2011). As a consequence of these design

6 features, correlation between the vignette factors are minimised to a value close to 0 (Rossi \& Nock,

7 1982), a situation which rarely occurs outside an experimental setting. The biggest advantage of

8 vignette experiments is, therefore, that they enable scholars to give a causal interpretation to the

9 measured effects of the included vignette factors on human decisions (Damelang \& Abraham, 2016;

10 Wallander, 2009). Moreover, as opposed to field experiments, vignette experiments have the added

11 benefit of creating the opportunity to ask additional questions to unravel the thinking process behind certain decisions and, consequently, to shed light on why we observe certain phenomena.

Vignette experiments have recently been the method of choice for a number of prominent studies in sociology and economics investigating human judgement (Ambuehl \& Ockenfels, 2017; Auspurg et al., 2017; Eriksson \& Kristensen, 2014; Mathew, 2017; Rivera \& Tilcsik, 2016). In particular, this type of experiment has been increasingly used to study dynamics in hiring decisions (Auer et al., 2016; Damelang \& Abraham, 2016; Di Stasio, 2014; Di Stasio \& Van de Werfhorst, 2016; Liechti et al., 2017; McDonald, 2017; Van Belle et al., 2018; Van Hoye \& Lievens, 2003). In this application of the vignette experimentation framework, participants have to judge fictitious candidates with divergent characteristics as vignette factors. As a consequence, these vignette experiments closely mimic reallife hiring situations, where HR professionals also take a number of characteristics into account when making hiring decisions. In our application, we included as a vignette factor whether job candidates applied to this vacancy under a job-vacancy referral system or on their own initiative. Exogenous variation in this factor would be hard to find in observational data. 
Regardless of these marked advantages, the chosen experimental approach has some limitations, which we should acknowledge. Firstly, contrary to field experiments, the data collection within a vignette experiment does not take place under real-life circumstances, and participants are aware that they are taking part in an experiment. This creates the risk of participants answering in a socially desirable way. However, we believe this to be less of a concern in our vignette experiment for a number of reasons. An important feature of a vignette experiment is that each participant is shown only a small number of vignettes, and these vary on a number of factors. Therefore, it is very difficult for the participant to ascertain the socially desirable answer (Auspurg et al., 2014; Liechti et al., 2017; Mutz, 2011). Vignette experiments have been able to identify unequal treatment, even when used to investigate socially sensitive topics such as unequal treatment based on gender and race (Auspurg \& Hinz, 2014). Moreover, if we did record some socially desirable answers in our experiment, the results described in this study could be seen as a lower bound of the true effects. ${ }^{3}$ Secondly, we only measure the effect of referral on hiring for individuals with a specific profile applying for a specific position. As a consequence, we cannot say to what extent our results are generalizable to settings with different jobs and candidate profiles (see also Van Belle et al., 2018).

The next subsections describe the specific institutional framework under study, the design of our vignettes, and the data gathering process.

\subsection{Institutional Framework}

Our study focusses on a job-vacancy referral scheme implemented by the PES of Flanders, the northern part of Belgium. In essence, this scheme matches open vacancies with jobseekers and, subsequently, forces jobseekers to apply for the vacancies matched to them. There are two types of possible referrals. In the case of a classic referral, a case worker, possibly aided by matching software, matches an open vacancy with an unemployed benefit recipient, who is then obliged to apply for it. In the alternative type of referral, the caseworker invites the unemployed person for a meeting, during which they go 
over a set of potentially relevant vacancies. If the unemployed person and the caseworker agree that a particular vacancy suits the person's profile, (s)he is obliged to apply. In both cases, non-compliance with the referral may result in a reduction or loss of benefits. In the context of monitoring this compliance, the PES informs the employer about the referral. This happens at, or soon after, the time of referral. ${ }^{4}$ So, in principle, the employer is aware that a candidate is referred by the PES prior to this

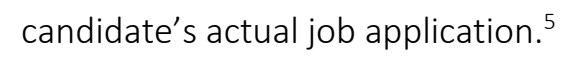

As a consequence, the policy under study consists of two components. Firstly, registered job seekers are matched with open vacancies, either electronically or by a case worker. Secondly, the job seeker is obliged to apply for the vacancy and will be sanctioned in the case of non-compliance. Both components of this intervention may have consequences on the demand-and supply-side of the labour market, which could be either positive or negative. At the supply side, the job seeker is incentivized to apply for more vacancies. Indeed, the job seeker is obliged to apply for matched vacancies. Moreover, as the job seeker becomes aware of the increased surveillance, he or she might apply for other vacancies to avoid future job referrals. On the demand-side, we can expect two opposing effects. First, because of the matching component, the referred candidates should be a better match for the vacancy than the average job candidate. This increased match quality could be either directly observable, or unobservable to prospective employers. In the second case, being matched to a vacancy by the PES might still send a positive signal of match quality to employers. On the other hand, the fact that the job seeker is obliged to apply for the vacancy might send the opposite signal to employers, namely that the job seeker merely applies to avoid being sanctioned.

Bollens and Cockx (2016) used a timing-of-events approach to investigate the effectiveness of this job-vacancy referral scheme in terms of entry to employment. They measured the total effect of the scheme, being the resultant of all supply- and demand-side factors of both components (i.e. the matching and the obligation component). They report substantial positive treatment effects both during the month of the referral and over the course of the following months. However, as this positive 
total effect of the referral measured by Bollens and Cockx (2016) combines supply-side and demand-

2 side effects, it remains interesting to unravel the underlying dynamics. Moreover, at the time of the evaluation performed by Bollens and Cockx (2016), employers were informed about the referral in approximately only $25 \%$ of the cases, so that demand-side dynamics might have been less influential at that time.

In the present study, we focus on the demand-side effects of the job-vacancy referral scheme, and more precisely, on the signals related to applying for a vacancy through this programme. The observable characteristics of our fictitious job candidates are orthogonal to their referral status (see below). Consequently, a potential signal of a better match quality only concerns characteristics unobservable from a résumé and might therefore be quantitatively less important in our setting. As a result, we mainly estimate the signal of being obliged to apply for a matching vacancy.

\subsection{Vignette Design}

We asked a sample of HR professionals described in the subsection below to evaluate a set of five vignettes, each describing one potential fictitious candidate for an open vacancy. These job applicants differed in the six vignette factors defined in Table 1 . The main factor of interest was the one indicating whether or not candidates were referred to the position by the PES. ${ }^{6}$ More precisely, and in line with reality, candidate summaries could either mention that the candidate applied for the position directly or was referred by the PES. In the latter case, it was mentioned explicitly that this entailed that the candidate was obliged to apply for this suitable vacancy. Besides this factor, applicants differed in gender (male or female), educational attainment (secondary education certificate or bachelor's degree), previous work experience (two or five years), whether they mentioned social activities (none or volunteering activities), and unemployment duration prior to the application (1 to 36 months). These vignette factors were chosen on the basis of a literature review of drivers of job-application success (Damelang \& Abraham, 2016; Di Stasio, 2014; Di Stasio \& Van de Werfhorst, 2016; Liechti et al., 2017; 
1 Van Belle et al., 2018) and an interview with three HR professionals. ${ }^{7}$ In addition, we ran a pilot study

2 with 30 master's students in Economics to test whether our vignettes were perceived as plausible and that no crucial information was omitted.

\section{$<$ Table 1 about here $>$}

After fully crossing all vignette levels for the six mentioned factors, we obtained a vignette universe of 1,152 (i.e. $2 \times 2 \times 2 \times 2 \times 2 \times 36$ ) vignettes. We used a D-efficient randomisation to minimise correlation between the different vignette factors. More concretely, following the algorithm in Auspurg and Hinz (2014), we selected 60 sets of 5 vignettes, allowing us to achieve a D-efficiency of 99.809.8

9 Each participant was randomly assigned one of these 60 sets. The resulting correlations between our vignette factors can be found in Table A1 (in Appendix A) and show that our randomisation approach was successful.

\subsection{Data Collection}

We conducted our experiment in January 2017 with Flemish recruiters. The experiment was part of a large-scale survey performed with individuals that selected themselves in a database of volunteers for participation in research on human resource management. At the start of this survey, the participants were asked whether they had been actively involved in the hiring process a minimum of five times during the past year. Participants who answered this question in a positive way had a $50 \%$ probability of being assigned to our experiment (and a 50\% probability of being assigned to the experiment of Van Belle et al. (2018)). In total, 234 recruiters took part in our experiment. Of these respondents, 29 left one or more questions unanswered, leaving us with a total sample of 205 participants. Each participant rated five vignettes, yielding a total of 1,025 at the participant-vignette level. ${ }^{9}$

As a first step, each participant received experimental instructions. They were introduced to their 
responsible for filling an open vacancy for a new counter assistant-we selected this occupation because it is common in a number of industries, thus increasing the probability that participants would be familiar with it. Participants were informed that the successful candidate had to be (i) customer orientated, (ii) service minded, and (iii) commercially orientated. Moreover, the company was looking for someone able to perform administrative tasks in an efficient and reliable way. No specific education or work experience was required. Subsequently, each participant was shown five vignettes (as described in the previous section). It was stressed that all five candidates had passed an initial screening by an administrative staff member. In line with the literature, the applicants' characteristics were presented in a tabulated way. Participants, though aware of participating in an experiment, were not informed of the goal or the topic of the experiment, which was framed in rather general terms.

With this information at hand, participants were asked to reveal, for each candidate, their hiring intentions. They were specifically asked to rate the statements 'The probability that I will invite this candidate for a job interview is high' and 'The probability that I will hire this candidate for the position is high' on a 7-point Likert scale. In the remainder of this article, these scales will be referred to as the 'interview scale' and the 'hiring scale', respectively.

In addition, in view of answering R3, participants were prompted to rate five statements (also on a 7-point Likert scale) linked to the different signals that could be sent by a job-vacancy referral prevalent in the literature and as described in Section 1. So, perceptions concerning the candidates' (i) motivation, (ii) intellectual abilities, (iii) social abilities, (iv) trainability, and (v) previous unfavourable evaluation by other employers were tested. The statements used can be found in Table A2. We limited the experimental survey to one statement per signal to keep the overall time taken up by the experiment within a reasonable limit (taking into account that each respondent was asked to review multiple profiles).

Finally, in view of answering R2, some personal characteristics of the respondents were surveyed, including their gender, age, nationality, educational attainment, frequency of hiring, and experience 
with the hiring process.

Panel A of Table 2 presents some summary statistics concerning the participants in our experiment. Participants had an average age of about 43 years, with most being Belgian nationals and having some form of tertiary education. They were slightly more likely to be female than male. A total of $46.8 \%$ of the respondents indicated that they recruited someone on at least a weekly basis, while 55.1\% indicated having at least ten years' experience as a recruiter.

\section{$<$ Table 2 about here $>$}

8

In columns (2) and (3) of Table 2 the research sample is split by the referral status of the judged job candidate. Column (4) presents the difference between these two columns as well as the results of a ttest to determine whether these differences are statistically significant. Given that each respondent judged five candidate profiles, our data are inherently nested. We control for this by clustering at the participant level. Overall, the information in Panel A of Table 2 allows us to conclude that referral status was successfully randomised over the participants.

\section{Results}

\subsection{Does Applying for a Job Under a Job Referral Scheme Yield Lower Hiring Chances?}

A first indication of the signalling effect of applying for a job under a job-vacancy referral scheme is given in Figure 1. On the left-hand side, the average rating on the interview and hiring scales by referral status is depicted. It is clear that candidates referred to the vacancy by the PES are both less likely to be invited for an interview $(p=0.000)$ and less likely to be hired $(p=0.000)$ for the position. The average rating on the interview (hiring) scale is $0.657(0.643)$ lower for referred candidates than for direct 
applicants. In other words, given that the standard deviation of the interview (hiring) scale is 1.608

2 (1.414), being referred to the vacancy decreases the probability of an interview (getting hired) by $40.9 \%$ (45.5\%) of a standard deviation. The same information can be inferred from Panel B of Table 2.

Due to our experimental set-up-the referral dummy is, by design, uncorrelated with any of the other observable candidate characteristics - these effects can be given a causal interpretation. In addition, due to the random allocation of vignette sets to participants, we do not expect any correlation with the participant characteristics. This is also confirmed when we estimate the following econometric model:

$$
Y=\alpha+\beta C C+\gamma P C+\delta R E F+\varepsilon .
$$

In this model, $R E F$ is the candidate's referral status ( 1 in case of referral, 0 in case of direct application); $C C$ is the vector of the other vignette factors mentioned in Subsection 2.2; and $P C$ is the vector of participant characteristics mentioned in the same subsection. The dependent variable of this model, $Y$, can be either the interview or hiring scale. $\beta, \gamma$, and $\delta$ are the (vectors of) parameters associated with $C C, P C$, and $R E F$ and $\alpha$ represents the intercept in this equation. Finally, standard error $\varepsilon$ is corrected for clustering of the observations at the participant level.

The estimation results of this model are reported in column (1) of Table 3 and Table A3, with the interview and hiring scales as respective outcomes. Again, in Panel A of this table, we observe that candidates who are referred to the position by the PES are less likely to be invited for an interviewthe related coefficient is substantial in both economic and statistical terms. This clearly indicates that being referred to a position by the PES - and, in particular, being obliged to apply for this position - has a negative signalling effect for the employers. This finding corroborates the qualitative evidence on the signalling effect of ALMP participation mentioned in Section 1 (Bellis et al., 2011; Bonoli \& Hinrichs, 2010; Ingold \& Stuart, 2014). Moreover, the negative signal of a job-vacancy referral could be part of 
the explanation for the unsatisfactory results of these programmes in terms of employment outcomes.

Finally, our finding indicates that the positive effect of the Flemish referral system on employment outcomes, as found in Bollens and Cockx (2016), could be even larger if this adverse signalling effect could be reduced. We return to this point in Section 4.

\section{< Table 3 about here >}

Concerning the other vignette factors, the estimated coefficients all have the expected signs. While gender has no effect on the likelihood of being invited for an interview, having a bachelor's degree (as opposed to a secondary-level education) and having five (as opposed to two) years' professional experience clearly enhances one's chances of being invited, as does mentioning volunteering activities. ${ }^{10}$ On the other hand, in line with what was found by Van Belle et al. (2018), the longer a candidate has been unemployed prior to the position, the lower her/his chances of being invited for an interview. If we turn to the coefficients related to the participant characteristics (in Panel B of Table 3), we see that female and older recruiters are more lenient in their judgement, while recruiters who are involved in the hiring process at least once a week tend to be stricter.

The corresponding estimation results when adopting the hiring scale as the outcome variable (Table A3, column (1)) are largely in line with the discussed results when using the interview scale as the dependent variable. However, the significant effect of recruiter gender disappears.

\subsection{Is this Effect Heterogeneous by Candidate and Subject Characteristics?}

To determine whether the signalling effect of the job-vacancy referral depends on other candidate characteristics, we re-estimate equation (1) including interaction terms between the referral dummy and each of the five other vignette factors. After including these interactions, the remaining coefficient of the referral dummy should be interpreted as the effect of a referral for a reference candidate, i.e. a male candidate with high school certification and two years' experience who has been unemployed for 
zero months and did not mention any social activities on his $\mathrm{CV}$. The results of this exercise are reported in column (2) of Table 3 and Table A3. We find that the signalling value of the job-vacancy referral scheme is not moderated by any of the other candidate characteristics. In particular, it is interesting to note that the negative effect of a PES referral does not vary with the length of the unemployment spell. Had we observed such an interaction effect, this could have been interpreted as suggestive evidence of employers assuming that the long-term unemployed simply apply via the PES to keep receiving benefits (without being intrinsically motivated to fill the vacancy).

Secondly, in column (3) of Table 3 and Table A3 we present the results of a similar analysis to study whether the effect of the job-vacancy referral is heterogeneous by type of recruiter. More concretely, compared to column (1), interaction terms between referral and the participant characteristics are adopted. In contrast to the candidate characteristics, the observed participant characteristics are not experimentally controlled and can, as a consequence, correlate with unobserved participant traits. Thus, the interaction effects presented in column (3) cannot be given a causal interpretation. However, we find that the effect of being referred to a vacancy is not heterogeneous by any of the participant characteristics.

\subsection{Which Signals Are Sent by Applying for a Job Under a Job Referral Scheme?}

In this subsection, we explore what exactly is signalled by the job-vacancy referral scheme, thereby examining why applying via a referral decreases one's hiring chances. The right-hand side of Figure 1 (and Panel $\mathrm{C}$ of Table 2) gives us a first indication of the empirical importance of the possible signals put forward in the literature and enumerated in Section 1. It is revealed that the candidates who apply for the open vacancy directly, without action or obligation by the PES, score better, on average, on all five statements related to these signals than those candidates who have been referred to the vacancy by the PES. So, referred candidates are, indeed, perceived as less motivated, less intellectually gifted, less socially gifted and less trainable, as well as having been rejected more often by other employers. 
These perceptions are statistically significant (at the $1 \%$ level), with the exception of the last one. In terms of economic significance, it is striking that the effect of referral on perceived motivation of the candidate is substantially higher than its effect on the other perception scales.

Finally, we estimate a mediation model, where these five potential signals related to referral are included jointly. This has two important advantages. Firstly, we can estimate the prominence of each signal independently. This is important as the signals potentially correlate with each other. ${ }^{11}$ Secondly, in addition to looking at the impact of the referral on the signals, the model takes the importance of the signals in terms of invitation (or hiring) probability into account as well. This enables us to look at what part of the total effect of the referral on hiring is explained by each signal. The estimated model consists of the following system of equations (in line with Hayes (2013) and Van Belle et al. (2018)):

$$
M_{i}=\alpha_{i}+\beta_{i} C C+\gamma_{i} P C+\delta_{i} R E F+\varepsilon_{i}
$$

$$
Y=\alpha^{\prime}+\beta^{\prime} C C+\gamma^{\prime} P C+\delta^{\prime} R E F+\theta M+\varepsilon^{\prime}
$$

In this system, $C C, P C, R E F$, and $Y$ are the same variables as those defined in the context of equation (1). In addition, $M$ is the vector of mediators capturing perceived motivation, intellectual abilities, social abilities, trainability, and evaluation by other employers, respectively. $\beta_{i}, \gamma_{i}$, and $\delta_{i}$ are the (vectors of) parameters associated with $C C, P C$, and $R E F$ in the equations with $M_{i}$ as a dependent variable, and $\alpha_{i}$ represents the intercept in these equations. $\beta^{\prime}, \gamma^{\prime}, \delta^{\prime}$, and $\alpha^{\prime}$ are the corresponding parameters in the equation with $Y$ as a dependent variable. Finally, $\theta$ is the vector parameters associated with the mediating signals in the latter equation. As a consequence, $\delta^{\prime}$ is the remaining direct effect of the referral after controlling for the five mediators. The products $\delta_{i} \theta_{i}$ are the indirect effects of the referral on $Y$ through each mediator $M_{i}$. In line with Hayes (2013), we estimate this system of six equations simultaneously and, as before, correct the standard errors $\varepsilon_{i}$ and $\varepsilon^{\prime}$ for clustering of the observations at the participant level. 
in Figure 2 (Figure A1). The corresponding full estimation results are reported in Table 4 (Table A4). Just as was the case with the overall signalling effect discussed in Section 3.1, the effect of the referral on each of the five perceptions concerning the candidate (i.e. the $\delta_{i}$ in our model) can be interpreted as causal effects as a consequence of the random assignment of a referral to the vignettes. In contrast, the effect of these perceptions on the interview (and hiring) scale (i.e. the $\theta_{i}$ in our model) cannot be given a causal interpretation as the included mediators could correlate with other, unobserved, signals related to applying under a job-vacancy referral system. As a consequence, also the mediation effects $\delta_{i} \theta_{i}$ should be seen as associations rather than as causal effects.

\section{< Figure 2 about here >}

\section{$<$ Table 4 about here >}

The left-hand side of Figure 2 shows the effect of the referral on each of the five mediators. Even after controlling for the other mediators, candidates with a referral are perceived as being less motivated, possessing less intellectual and social abilities, and being less trainable. Again, the impact of a referral on perceived motivation is substantially larger than its impact on any of the other potential signals. Finally, being referred to the vacancy does not have any effect on the perceived evaluation by other employers, both in statistical and economic terms.

The right-hand side of Figure 2 reports the effect of the different signals on the likelihood of being invited for a job interview. We find that having higher perceived motivation, higher perceived intellectual or social abilities, and a better perceived evaluation by other employers all significantly enhance one's chances of being invited for a job interview. In contrast with what is expected based on queuing theory (Thurow, 1975), we find that perceived trainability does not have any impact on the probability of being invited for a job interview.

By multiplying the left- and right-hand sides of this figure, we can decompose the total effect of a referral on the likelihood of being invited for a job interview $(\delta=-0.655 ; p=0.000)$ found in Subsection 
13.1 into a remaining direct effect and indirect effects via perceptions concerning the candidate's

2 motivation, intellectual ability, social ability, trainability, and evaluation by other employers. We find a

3 substantial mediation effect related to perceived motivation $\left(\delta_{1} \theta_{1}=-0.492 ; p=0.000\right)$ : $75.1 \%$ (i.e.

$4-0.492 /-0.655)$ of the total effect of a referral on the interview probability is explained by this referral constituting a negative signal of motivation. Additionally, being referred to a vacancy also constitutes a signal of fewer intellectual $\left(\delta_{2} \theta_{2}=-0.042 ; p=0.010\right)$ and social $\left(\delta_{3} \theta_{3}=-0.027 ; p=0.043\right)$ abilities. However, these coefficients are very small compared to the mediation effect related to perceived motivation. The measured direct effect $\left(\delta^{\prime}=-0.090 ; p=0.235\right)$ is the part of the total effect that remains unexplained by the inclusion of the mediators. Given that this direct effect is not significantly different from zero, we can infer that the signals included in our mediation model fully explain the effect of a referral on interview chances. The quarter of the negative signal that is not explained by a perceived lower motivation could be dominated by other elements of the vacancy referral scheme that are less important in our experimental design, for example the perceived match quality of the candidate and the job.

These findings corroborate the evidence from qualitative research suggesting that referral is seen as a signal of lower motivation (Bellis et al., 2011; Ingold \& Stuart, 2014). They seem to indicate that employers do view the candidates who are obliged to apply by the PES as candidates who mainly apply in order to continue receiving benefits, which contrasts with the insignificant interaction effect between referral and unemployment duration, as elaborated on in Subsection 3.2.

The results of the mediation analysis with the probability of being hired for the position as the outcome variable are largely similar to the results with the probability of a job interview as the outcome variable. An alternative representation of these mediation results, in the sense of Heckman et al. 23 (2013), is given in Table A5. 


\section{4. Conclusion}

This article contributed to the literature on the effectiveness of active labour market policies. As argued, the evaluation literature has mainly focused on measuring the overall effectiveness of these programmes, with mixed results. Therefore, in our opinion, the logical next step to take in this literature is to explain why this unsatisfactory effectiveness exists. In this study, we investigated the signalling effect of applying for a job through a vacancy referral scheme, thereby focussing on demand-side dynamics. As the job-vacancy referral scheme may also have supply-side effects, as reviewed in Subsection 2.1, future research could look into these supply-side dynamics and, especially, the added value of the matching component of the referral scheme in this perspective.

Based on a vignette experiment with HR professionals, we provided first causal evidence for a large negative effect of being referred on one's probability of getting invited to a job interview and finally getting the job. In addition, our experimental design allowed us to explore what exactly is signalled by a job-vacancy referral, testing five potential signals documented in the literature: lower motivation, lower intellectual abilities, lower social abilities, lower trainability, and poor evaluation by other employers. The single most important explanation appeared to be that candidates applying for a position after a PES referral were perceived as significantly less motivated. This corroborates earlier qualitative findings by Bonoli and Hinrichs (2010), Bellis et al. (2011), and Ingold and Stuart (2014).

Besides their academic relevance, our results have substantial policy implications. Our findings are consistent with two possible scenarios. Either referred candidates are indeed less motivated or the referred candidates are, in reality, at least on average, not less motivated than other candidates. In the first situation, it is important to know whether those referred are intrinsically less motivated or whether it is the referral which causes the lower motivation. If those referred are intrinsically less motivated, the PES should link the referrals to other policies to increase the benefit recipient's motivation. If it is the referral that is lowering the benefit recipient's motivation, one might question the usefulness of 
the referral scheme. If, on the other hand, the second scenario is the true scenario, it is important to reverse the negative perception of referred applicants. We see two ways of doing this. One way would be simply not to inform employers of the referral status of applicants. As aforementioned, at the time of Bollens and Cockx's (2016) study, the employer was only informed of a candidate being referred by the PES in approximately $25 \%$ of the cases. As they found a large positive effect of the referral on jobfinding probabilities, this suggests that not informing employers about a referral could indeed mitigate the negative effect on hiring probabilities. However, if the unemployed person is aware that the employer is not informed about the existence of the referral, and consequently, the PES cannot effectively monitor compliance, this might lower the overall effectiveness of the referral as there will no longer be a threat effect. Another way would entail the PES informing employers better that the referred candidates have gone through an initial screening (by the PES) and should therefore be a better match to the vacancy than other candidates. Overall, our findings suggest that there is room for improvement in the implementation of the vacancy referral scheme in Flanders.

\section{References}

Albanese, A., Cockx, B., \& Thuy, Y. (2016). Working time reductions at the end of the career. Do they prolong the time spent in employment? (IZA Discussion Papers, 9619)

Ambuehl, S., \& Ockenfels, A. (2017). The ethics of incentivizing the uninformed: A vignette study. American Economic Review, 107, 91-95.

Arrow, K. J. (1973). The theory of discrimination. In O. Ashenfelter \& A. Rees (Eds.), Discrimination in labour markets. Princeton: Princeton University Press.

Auer, D., Bonoli, G., Fossati, F., \& Liechti, F. (2016). The matching hierarchies model: Evidence from a survey experiment on employers' hiring intent of immigrant applicants. Unpublished manuscript. 
Auspurg, K., \& Hinz, T. (2014). Factorial survey experiments. Thousand Oaks: Sage.

Auspurg, K., Hinz, T., Liebig, S., \& Sauer, C. (2014). The factorial survey as a method for measuring sensitive issues. In U. Engel, B. Jann, P. Lynn, A. Scherpenzeel, \& P. Sturgis (Eds.), Improving survey methods: Lessons from recent research. New York: Routledge.

Auspurg, K., Hinz, T., \& Sauer, C. (2017). Why should women get less? Evidence on the gender pay gap from multifactorial survey experiments. American Sociological Review, 82, 179-210.

Baert, S., \& Vujić, S. (2016). Immigrant volunteering: A way out of labour market discrimination? Economics Letters, 146, 95-98.

Baert, S., \& Vujic, S. (in press). Does it pay to care? Volunteering and employment opportunities. Journal of Population Economics. DOI: 10.1007/s00148-017-0682-8.

Banerjee, A. (1992). A simple model of herd behaviour. Quarterly Journal of Economics, 107, 797-817.

Bellis, A., Sigala, M., and Dewson, S. (2011). Employer engagement and Jobcentre Plus, Research Report No. 742, Sheffield: DWP.

Bikhchandani, S., Hirshleifer, D., \& Welch, I. (1992). A theory of fads, fashion, custom and cultural change as informational cascades. Journal of Political Economy, 100, 992-1026.

Blanchard, O. J., \& Diamond, P. (1994). Ranking, unemployment duration, and wages. Review of Economic Studies, 61, 417-434.

Bollens, J., \& Cockx, B. (2016). Effectiveness of a job vacancy referral scheme. WSE Report 2016, 2.

Bonoli, G., \& Hinrichs, K. (2012). Statistical discrimination and employers' recruitment: Practices for low-skilled workers. European Societies, 14(3), 338-361.

Burtless, G. (1985). Are targeted wage subsidies harmful? Evidence from a wage voucher experiment. ILR Review, 39(1), 105-114.

Card, D., Kluve, J., \& Weber, A. (2010). Active labour market policy evaluations: A meta- 
analysis. Economic Journal, 120(548).

Card, D., Kluve, J., \& Weber, A. (2015). What works? A meta analysis of recent active labour market program evaluations (IZA Discussion Papers, 9236).

Cozzi, G., Mantovan, N., \& Sauer, R. M. (2013). Does it pay to work for free? Wage returns and gender differences in the market for volunteers. Oxford Bulletin of Economics and Statistics, 79(6), 10181045

Crépon, B., Gurgand, M., Kamionka, T., \& Lequien, L. (2013). Is counseling welfare recipients costeffective? Lessons from a random experiment (No. 2013-01). Centre de Recherche en Economie et Statistique.

Damelang, A., \& Abraham, M. (2016). You can take some of it with you! Zeitschrift für Soziologie, 45, 91-106.

Day, K. M., \& Devlin, R. A. (1997). Can volunteer work help explain the male-female earnings gap? Applied Economics, 29(6), 707-721. 106.

Engström, P., Hesselius, P., \& Holmlund, B. (2012). Vacancy referrals, job search, and the duration of 
Eriksson, T., \& Kristensen, N. (2014). Wages or fringes? Some evidence on trade-offs and sorting. Journal of Labor Economics, 32, 899-928.

Falk, A., Lalive, R., \& Zweimüller, J. (2005). The success of job applications: a new approach to program evaluation. Labour Economics, 12(6), 739-748.

Fougère, D., Pradel, J., \& Roger, M. (2009). Does the public employment service affect search effort and outcomes? European Economic Review, 53(7), 846-869.

Greenberg, D. H., Michalopoulos, C., \& Robins, P. K. (2003). A meta-analysis of government-sponsored training programs. ILR Review, 57(1), 31-53.

Hackl, F., Halla, M., Pruckner, G. J. (2007). Volunteering and Income - The Fallacy of the Good Samaritan? Kyklos, 60, 77-104.

Heckman, J. J., LaLonde, R. J., \& Smith, J. A. (1999). The economics and econometrics of active labour market programs. Handbook of Labour Economics, 3, 1865-2097.

Heckman, J. J., Pinto, R., \& Savelyev, P. (2013). Understanding the Mechanisms through Which an Influential Early Childhood Program Boosted Adult Outcomes. American Economic Review, 103, $2052-2086$.

Ingold, J., \& Stuart, M. (2015). The demand-side of active labour market policies: a regional study of employer engagement in the Work Programme. Journal of Social Policy, 44(3), 443-462.

Jasso, G. (2006). Factorial survey methods for studying beliefs and judgments. Sociological Methods \& Research, 34, 334-423.

Jespersen, S. T., Munch, J. R., \& Skipper, L. (2008). Costs and benefits of Danish active labour market programmes. Labour Economics, 15(5), 859-884.

23 Kluve, J. (2010). The effectiveness of European active labour market programs. Labour 
Liechti, F., Fossati, F., Bonoli, G., \& Auer, D. (2017). The signalling value of labour market programmes. European Sociological Review, 33(2), 257-274.

Martin, J. P. (2014). Activation and active labour market policies in OECD countries: stylized facts and evidence on their effectiveness (IZA Policy Papers, 84).

Martin, J. P., \& Grubb, D. (2001). What works and for whom: A review of OECD countries' experiences with active labour market policies. Swedish Economic Policy Review, 8, 9-56.

Mathew, S. (2017). How the second-order free rider problem is solved in a small-scale society. American Economic Review, 107, 578-581.

McDonald, P. (2017). Improving our understanding of employer decision-making thanks to factorial survey analysis. (LIVES Working paper, 2017/61).

Moscarini, G. (1997). Unobserved heterogeneity and unemployment duration: A fallacy of composition. Unpublished manuscript.

Mutz, D. C. (2011). Population-based survey experiments. Princeton: Princeton University Press.

Prouteau, L., \& Wolff, F. C. (2006). Does volunteer work pay off in the labour market? Journal of SocioEconomics, 35(6), 992-1013.

Rivera, L. A., \& Tilcsik, A. (2016). Class advantage, commitment penalty: The gendered effect of social class signals in an elite labour market. American Sociological Review, 81, 1097-1131.

Rossi, P. H., \& Nock, S. L. (1982). Measuring social judgments: The factorial survey approach. Thousand Oaks: Sage.

Sauer, R. M. (2015). Does it pay for women to volunteer? International Economic Review, 56(2), 537564.

Spence, M. (1973). Job market signalling. Quarterly Journal of Economics, 87, 355-374. 
1 Thurow, L. C. (1975). Generating inequality: Mechanisms of distribution in the U.S. economy. New York: Basic Books.

3 Van Belle, E., Di Stasio, V., Caers, R., De Couck, M., \& Baert, S. (2018). Why Are Employers Put Off by $4 \quad$ Long Spells of Unemployment? European Sociological Review. DOI: 10.1093/esr/jcy039.

5 Van Den Berg, G. J., Hofmann, B., \& Uhlendorff, A. (2016). The role of sickness in the evaluation of job search assistance and sanctions. (IZA Discussion Papers, 9626).

van den Berg, G. J., Kjærsgaard, L., \& Rosholm, M. (2014). To meet or not to meet, that is the question: Short-run effects of high-frequency meetings with case workers. (IFAU Working Paper, 2014:6). van den Berg, G. J., \& van der Klaauw, B. (2006). Counseling and monitoring of unemployed workers: Theory and evidence from a controlled social experiment. International Economic Review, 47(3), 895-936.

van den Berg, G. J., \& Vikström, J. (2014). Monitoring job offer decisions, punishments, exit to work, and job quality. Scandinavian Journal of Economics, 116(2), 284-334.

14 Van Hoye, G., \& Lievens, F. (2003). The effects of sexual orientation on hirability ratings: An experimental study. Journal of Business and Psychology, 18, 15-30.

16 Vishwanath, T. (1989). Job search, stigma effect, and escape rate from unemployment. Journal of Labor Economics, 7, 487-502. 


\section{Figure 1.}

Differences in Average Ratings by Referral Status of the Candidate

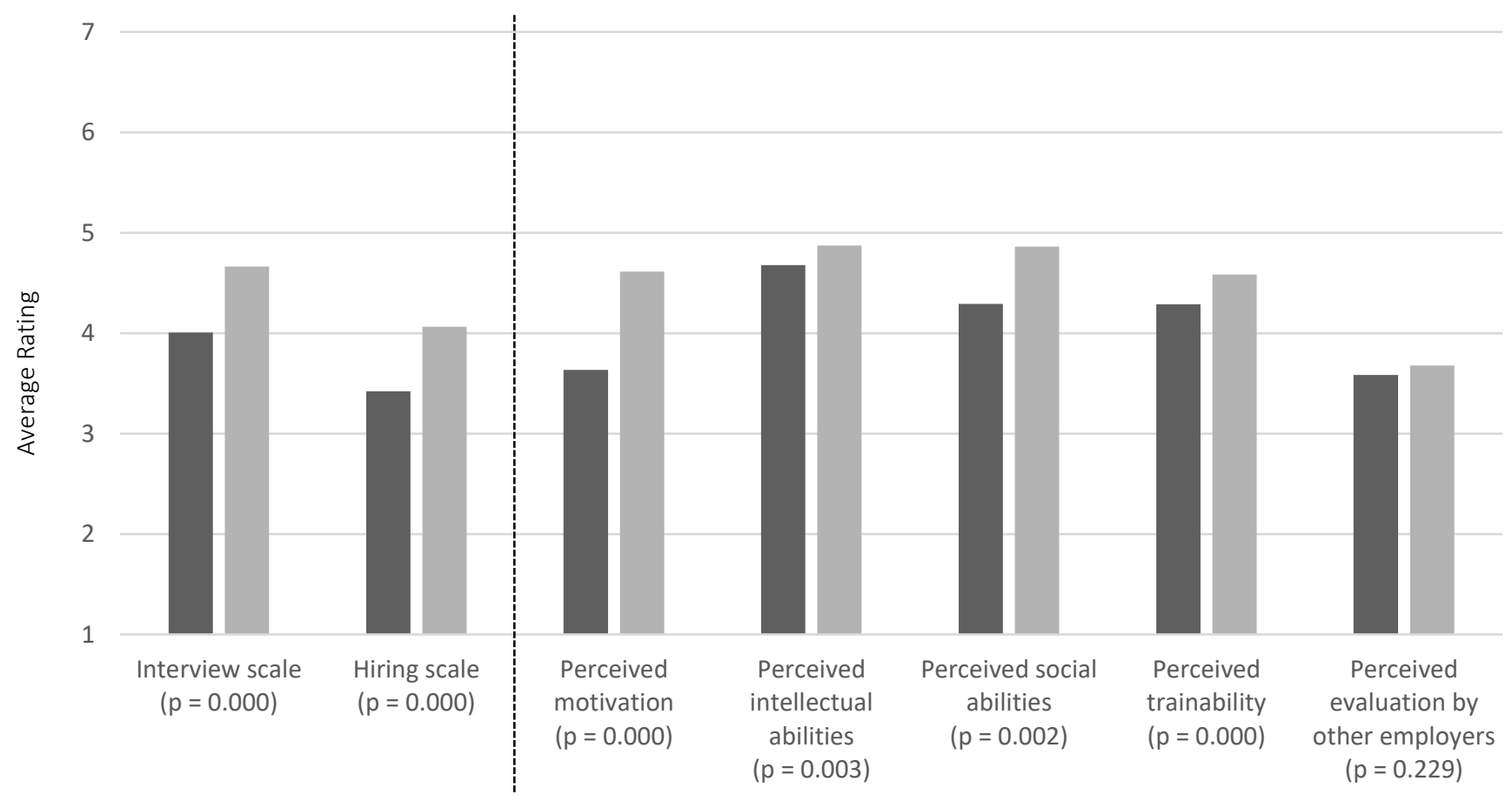

- Referral No referral

Note. More information concerning the used scales can be found in Subsection 2.3. T-tests are performed to test whether the presented differences are significantly different from 0. Standard errors are corrected for clustering of the observations at the participant level. 
Figure 2.

Mediation Model with Interview Scale as Outcome

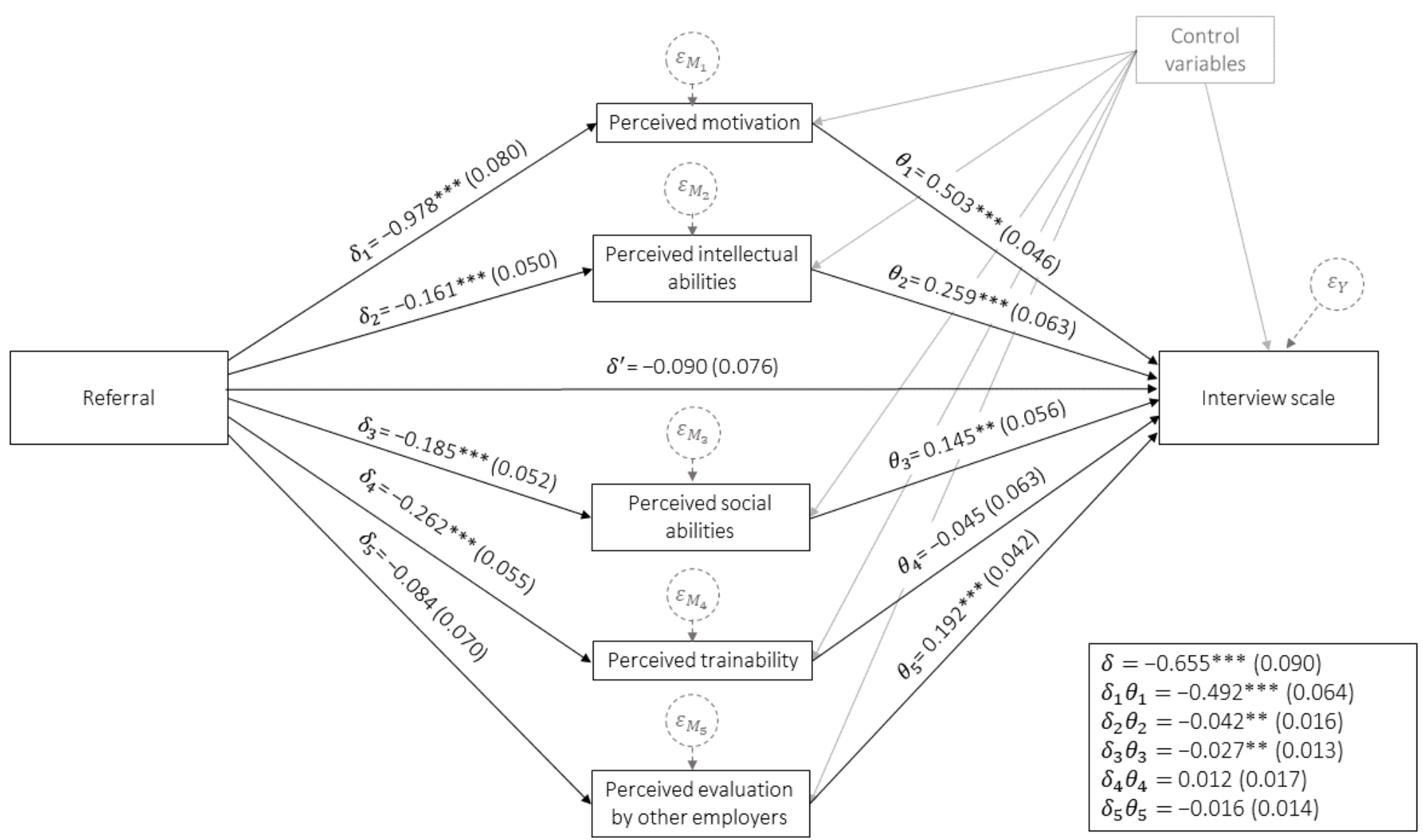

Note. The presented statistics are coefficient estimates (and standard errors in parentheses) for the mediation model outlined in Subsection 3.3. $\delta$ stands for the total effect, $\delta^{\prime}$ for the direct effect, and $\delta_{i} \theta_{i}$ for the indirect effects of a referral on the likelihood of an interview invitation passing through mediator $M_{i}$. Standard errors are corrected for clustering of the observations at the participant level. The confidence intervals for the mediation effects are based on 10,000 bootstrap samples. ${ }^{* * *}\left({ }^{* *}\right)\left(\left({ }^{*}\right)\right)$ indicates significance at the $1 \%(5 \%)((10 \%))$ significance level. 
Table 1.

Vignette Factors and Levels

\begin{tabular}{ll}
\hline \hline Vignette factors & Vignette levels \\
\hline Gender & $\{$ Male, Female $\}$ \\
Highest obtained educational certification & $\{$ Secondary education, Bachelor's degree $\}$ \\
Previous work experience & $\{$ Two years' experience, Five years' experience $\}$ \\
Mentioned social activities & $\{$ None, Volunteering $\}$ \\
Unemployment duration & $\{1$ month, 2 months, ..., 36 months $\}$ \\
Referral & \{Referred by the PES, Direct application $\}$ \\
\hline \hline
\end{tabular}

Note. PES stands for the Public Employment Service (of Flanders). The factorial product of the vignette levels $(2 \times 2 \times 2 \times 2 \times$ $36 \times 2$ ) resulted in 1,152 possible combinations. Sets of five vignettes were drawn from this vignette universe using a D-efficient design (D-efficiency: 99.809; Auspurg \& Hinz, 2014) and distributed at random to the participants as described in Subsection 2.2. This guaranteed that the vignette factors were nearly orthogonal, as shown in Table A1. 
Table 2.

Summary Statistics by Referral Status of the Candidate

\begin{tabular}{|c|c|c|c|c|}
\hline & \multicolumn{3}{|c|}{ Mean } & \multirow{3}{*}{$\begin{array}{l}\text { Difference: } \\
\text { (3) - (2) }\end{array}$} \\
\hline & Full sample & $\begin{array}{c}\text { Subsample: } \\
\text { Referral }\end{array}$ & $\begin{array}{l}\text { Subsample: } \\
\text { No referral }\end{array}$ & \\
\hline & $N=1,025$ & $N=521$ & $N=504$ & \\
\hline & (1) & $(2)$ & (3) & (4) \\
\hline \multicolumn{5}{|l|}{ A. PARTICIPANT CHARACTERISTICS } \\
\hline Female gender & 0.566 & 0.564 & 0.567 & $-0.003[0.228]$ \\
\hline Age & 43.024 & 43.177 & 42.867 & $0.310[0.966]$ \\
\hline Foreign nationality & 0.093 & 0.094 & 0.091 & $0.003[0.345]$ \\
\hline \multicolumn{5}{|l|}{ Highest obtained educational certification } \\
\hline Secondary education or lower & 0.093 & 0.100 & 0.085 & $0.014 *[1.860]$ \\
\hline Tertiary education: outside university & 0.429 & 0.436 & 0.423 & $0.013[0.950]$ \\
\hline Tertiary education: university & 0.478 & 0.464 & 0.492 & $-0.028 * *[1.993]$ \\
\hline Frequency of hiring: weekly & 0.468 & 0.468 & 0.468 & $0.001[0.005]$ \\
\hline Experience as HR professional: $\geq 10$ years & 0.551 & 0.559 & 0.544 & $0.015[1.074]$ \\
\hline \multicolumn{5}{|l|}{ B. EVALUATION: INTERVIEW AND HIRING DECISIONS } \\
\hline Interview scale & 4.329 & 4.006 & 4.663 & $-0.657 * * *[6.548]$ \\
\hline Hiring scale & 3.739 & 3.422 & 4.065 & $-0.643 * * *[7.324]$ \\
\hline \multicolumn{5}{|l|}{ C. EVALUATION: PERCEIVED CANDIDATE TRAITS } \\
\hline Perceived motivation & 4.115 & 3.635 & 4.611 & $-0.976 * * *[11.736]$ \\
\hline Perceived intellectual abilities & 4.774 & 4.678 & 4.873 & $-0.195 * * *[3.054]$ \\
\hline Perceived social abilities & 4.386 & 4.290 & 4.861 & $-0.196 * * *[3.173]$ \\
\hline Perceived trainability & 4.433 & 4.288 & 4.583 & $-0.295 * * *[4.649]$ \\
\hline Perceived evaluation by other employers & 3.629 & 3.582 & 3.679 & $-0.097[1.207]$ \\
\hline
\end{tabular}

Note. More information concerning the scales mentioned in Panel B and Panel C can be found in Subsection 2.3. T-tests are performed to test whether the presented differences are significantly different from 0 . Standard errors are corrected for clustering of the observations at the participant level. ${ }^{* * *}\left({ }^{* *}\right)((*))$ indicates significance at the $1 \%(5 \%)((10 \%))$ significance level. T-statistics are between brackets. 
Table 3.

Multivariate Analysis: Regression Analysis with Interview Scale as Outcome

\begin{tabular}{|c|c|c|c|}
\hline Explanatory variables & (1) & (2) & (3) \\
\hline \multicolumn{4}{|l|}{ A. CANDIDATE CHARACTERISTICS } \\
\hline Female gender & $0.075(0.074)$ & $0.036(0.117)$ & $0.083(0.074)$ \\
\hline Bachelor's degree & $0.344^{* * *}(0.083)$ & $0.385^{* * *}(0.123)$ & $0.356^{* * *}(0.083)$ \\
\hline Five years' experience & $0.265^{* * *}(0.080)$ & $0.360^{* * *}(0.111)$ & $0.264 * * *(0.079)$ \\
\hline Unemployment duration & $-0.053^{* * *}(0.004)$ & $-0.057^{* * *}(0.005)$ & $-0.053^{* * *}(0.004)$ \\
\hline Volunteering & $0.356^{* * *}(0.067)$ & $0.388^{* * *}(0.108)$ & $0.360 * * *(0.068)$ \\
\hline Referral & $-0.655^{* * *}(0.090)$ & $-0.690 * * *(0.260)$ & $-0.590 * * *(0.500)$ \\
\hline Referral $\times$ Female gender & & $0.067(0.179)$ & \\
\hline Referral $\times$ Bachelor's degree & & $-0.096(0.176)$ & \\
\hline Referral $\times$ Five years' experience & & $-0.185(0.187)$ & \\
\hline Referral $\times$ Unemployment spell & & $0.009(0.007)$ & \\
\hline Referral $\times$ Volunteering & & $-0.048(0.169)$ & \\
\hline \multicolumn{4}{|l|}{ B. PARTICIPANT CHARACTERISTICS } \\
\hline Female gender & $0.341^{* *}(0.161)$ & $0.344^{* *}(0.161)$ & $0.363^{* *}(0.167)$ \\
\hline Age & $0.027^{* * *}(0.009)$ & $0.027^{* * *}(0.009)$ & $0.018 *(0.010)$ \\
\hline \multicolumn{4}{|l|}{ Highest obtained educational certification } \\
\hline Secondary education or lower & $0.005(0.269)$ & $-0.002(0.270)$ & $-0.216(0.319)$ \\
\hline Tertiary education: outside university & $0.074(0.147)$ & $0.067(0.148)$ & $0.119(0.164)$ \\
\hline \multicolumn{4}{|l|}{ Tertiary education: university (reference) } \\
\hline Frequency of hiring: weekly & $-0.393^{* *}(0.168)$ & $-0.391 * *(0.168)$ & $-0.460 * *(0.191)$ \\
\hline Experience as HR professional: $\geq 10$ years & $-0.239(0.177)$ & $-0.240(0.178)$ & $-0.153(0.198)$ \\
\hline Referral $\times$ Female gender & & & $-0.044(0.177)$ \\
\hline Referral $\times$ Age & & & $0.017(0.011)$ \\
\hline Referral $\times$ Secondary education or lower & & & $0.405(0.305)$ \\
\hline Referral $\times$ Tertiary education: outside university & & & $-0.077(0.187)$ \\
\hline Referral $\times$ Frequency of hiring: weekly & & & $0.120(0.183)$ \\
\hline Referral $\times$ Experience as HR professional: $\geq 10$ years & & & $-0.182(0.205)$ \\
\hline Observations & & 1,025 & \\
\hline
\end{tabular}

Note. The presented statistics are coefficient estimates and standard errors in parentheses for the regression model outlined in Subsection 3.2. Standard errors are corrected for clustering of the observations at the participant level. ${ }^{* * *}\left({ }^{* *}\right)\left(\left({ }^{*}\right)\right)$ indicates significance at the $1 \%(5 \%)((10 \%))$ significance level. 
Table 4.

Multivariate Analysis: Mediation Analysis with Interview Scale as Outcome

\begin{tabular}{|c|c|c|c|c|c|c|}
\hline \multirow[b]{2}{*}{ Explanatory variables } & \multicolumn{6}{|c|}{ Outcome variables } \\
\hline & Perceived motivation & $\begin{array}{c}\text { Perceived intellectual } \\
\text { abilities }\end{array}$ & $\begin{array}{l}\text { Perceived social } \\
\text { abilities }\end{array}$ & Perceived trainability & $\begin{array}{c}\text { Perceived evaluation } \\
\text { by other employers }\end{array}$ & Interview scale \\
\hline \multicolumn{7}{|l|}{ A. CANDIDATE CHARACTERISTICS } \\
\hline Female gender & $-0.080(0.074)$ & $0.157^{* * *}(0.054)$ & $0.185 * * *(0.052)$ & $0.142^{* * *}(0.053)$ & $0.076(0.063)$ & $0.040(0.058)$ \\
\hline Bachelor's degree & $0.018(0.065)$ & $0.991^{* * *}(0.066)$ & $0.233 * * *(0.054)$ & $0.775^{* * *}(0.067)$ & $0.215^{* * *}(0.065)$ & $0.038(0.079)$ \\
\hline Five years' experience & $0.127 *(0.066)$ & $0.098 * *(0.048)$ & $0.070(0.053)$ & $0.020(0.053)$ & $-0.037(0.066)$ & $0.174^{* * *}(0.067)$ \\
\hline Unemployment duration & $-0.029 * * *(0.003)$ & $-0.019 * * *(0.003)$ & $-0.019 * * *(0.003)$ & $-0.025 * * *(0.003)$ & $-0.049 * * *(0.004)$ & $-0.023 * * *(0.004)$ \\
\hline Volunteering & $0.268 * * *(0.066)$ & $0.122^{* * *}(0.046)$ & $0.949 * * *(0.068)$ & $0.152^{* * *}(0.052)$ & $0.219 * * *(0.066)$ & $0.017(0.063)$ \\
\hline Referral & $-0.978 * * *(0.080)$ & $-0.161^{* * *}(0.050)$ & $-0.185 * * *(0.052)$ & $-0.262 * * *(0.055)$ & $-0.084(0.070)$ & $-0.090(0.076)$ \\
\hline \multicolumn{7}{|l|}{ B. PARTICIPANT CHARACTERISTICS } \\
\hline Female gender & $-0.014(0.106)$ & $0.082(0.101)$ & $0.058(0.077)$ & $0.080(0.107)$ & $-0.115(0.138)$ & $0.344 * *(0.141)$ \\
\hline Age & $0.012 *(0.007)$ & $0.001(0.005)$ & $-0.001(0.005)$ & $0.001(0.006)$ & $0.015 *(0.008)$ & $0.018^{* *}(0.007)$ \\
\hline \multicolumn{7}{|l|}{ Highest obtained educational certification } \\
\hline Secondary education or lower & $-0.161(0.219)$ & $0.173(0.147)$ & $0.191(0.137)$ & $0.063(0.180)$ & $0.184(0.204)$ & $-0.019(0.252)$ \\
\hline Tertiary education: outside university & $-0.158(0.103)$ & $0.008(0.104)$ & $-0.042(0.078)$ & $0.095(0.100)$ & $0.288^{* *}(0.127)$ & $0.107(0.122)$ \\
\hline \multicolumn{7}{|l|}{ Tertiary education: university (reference) } \\
\hline Frequency of hiring: weekly & $-0.123(0.119)$ & $-0.278 * * *(0.103)$ & $-0.181 * *(0.091)$ & $-0.119(0.106)$ & $-0.146(0.153)$ & $-0.210(0.143)$ \\
\hline Experience as HR professional: $\geq 10$ years & $-0.086(0.134)$ & $0.039(0.117)$ & $-0.057(0.093)$ & $0.020(0.118)$ & $-0.075(0.164)$ & $-0.182(0.148)$ \\
\hline \multicolumn{7}{|l|}{ C. Perceived CANDIDATE TRAITS } \\
\hline Perceived motivation & & & & & & $0.503^{* * *}(0.046)$ \\
\hline Perceived intellectual abilities & & & & & & $0.259 * * *(0.063)$ \\
\hline Perceived social abilities & & & & & & $0.144 * *(0.056)$ \\
\hline Perceived trainability & & & & & & $-0.045(0.063)$ \\
\hline Perceived evaluation by other employers & & & & & & $0.192^{* * *}(0.042)$ \\
\hline Observations & \multicolumn{6}{|c|}{1,025} \\
\hline
\end{tabular}

Note. The presented statistics are coefficient estimates and standard errors in parentheses for the mediation model outlined in Subsection 3.3. Standard errors are corrected for clustering of the observations at the participant level. ${ }^{* * *}\left({ }^{* *}\right)((*))$ indicates significance at the $1 \%(5 \%)((10 \%))$ significance level. 


\section{ENDNOTES}

${ }^{1}$ We elaborate on the specifics of this policy and the theoretical channels through which it might affect our experimental outcomes in Subsection 2.1.

2 Throughout the present article, we assume that employers are aware if a candidate has been referred to a vacancy. As explained in Subsection 2.1 , this is a realistic assumption in the case of the referral scheme central to our study.

${ }^{3}$ To determine whether or not this is the case, it would be interesting to replicate our study by means of a field experiment, although it would not be straightforward to inform employers on the referral status of applicants in a realistic way within such an experiment, and this type of experiment would not provide insight into the specific signals of the scheme.

${ }^{4}$ More concretely, this happens automatically via a software program for employers with a profile in the PES database and manually-but very soon after the matching is done-for employers without such a profile.

${ }^{5}$ The information on the referral procedure was given to us by caseworkers of the PES of Flanders. A transcript of this information is available upon request.

${ }^{6}$ As argued in Subsection 2.1, it is highly likely that a Flemish employer is aware that a candidate is referred to a position by the PES so that this is a realistic vignette factor.

7 Transcripts of these interviews are available upon request.

8 This design maximises both orthogonality and level balance, thereby enhancing statistical precision (Auspurg \& Hinz, 2014). Formally, this approach maximises the D-efficiency, which is given by the following formula:

$$
D-\text { efficiency }=100 * \frac{1}{n_{s^{*}}\left|\left(X^{\prime} X\right)^{-1}\right|^{\frac{1}{p}}}=100 *\left(\frac{1}{n_{s}} *\left|X^{\prime} X\right|^{\frac{1}{p}}\right),
$$

where $X$ is the vector of the vignette variables, $n_{s}$ indicates the number of vignettes in the sample and $p$ presents the number of regression coefficients (including the intercept) in the analysis of the experimental data. For more information, we refer to Auspurg and Hinz (2014).

${ }^{9}$ Liechti et al. (2017) argue that the response rate in this type of experiment is of lesser importance as long as each profile is judged by multiple participants. This is the case here, as each profile was judged by an average of 3.417 participants (i.e. 205 [respondents] divided by 60 [sets of profiles]).

${ }^{10}$ The fact that mentioning volunteering activities appears to have a larger effect on one's hiring chances than having completed a higher education programme or having three years of additional work experience might seem surprising. However, this result is in line with what is found by Baert and Vujić (in press), who show by means of a field experiment that job candidates mentioning volunteering receive one-third more interview invitations. Moreover, multiple studies have shown that volunteering activities appear to have a positive impact on earnings (Day \& Devlin, 1997, 1998; Detollenaere et al., 2017; Gozzi et al., 2013; Hackl et al., 2007; Prouteau \& Wolff, 2006; Sauer, 2015) and that this volunteer work, when done by ethnic minorities, may even cancel out ethnic discrimination in the labour market (Baert \& Vujic, 2016).

11 Indeed, these correlations range from $r=0.135$ (between perceived social abilities and perceived evaluation by other employers) to $r=0.632$ (between perceived social abilities and trainability). 